\title{
Application of Bradford's law to the evaluation of book collection of library of Bhabha Atomic Research Centre
}

\author{
Priya Girap*, Tara Ashok, Karanam Bhanumurthy \\ Scientific Information Resource Division, Bhabha Atomic Research Centre, Trombay, Mumbai, Maharashtra, India
}

\begin{abstract}
Evaluation of the collection is a very important step toward the development of good and balanced collection in the library. Bhabha Atomic Research Centre (BARC) library is a special scientific research library, which provides exhaustive information in the field of nuclear science and technology and allied fields. In this study, we have used Bradford's law to evaluate and analyze the book collection of BARC library. A total collection of 94,450 books was considered for the study. The collection was divided into 27 main subject headings with the help of Universal Decimal Classification class numbers. These headings were then considered for analysis of application of Bradford's law to the collection. The analysis shows that nuclear physics with 14,937 (15.81\%) books topped the list followed by nuclear engineering with $12,543(13.28 \%)$ books, chemistry with 11,447 (12.12\%) books, medical sciences with 8545 (9.05\%) books, and mathematics with $5174(5.48 \%)$ books. These subject headings are then arranged into three Bradford's zones to find the core subjects of the collection. It shows that nuclear physics and nuclear engineering are the $I^{\text {st }}$ zone that is, core subject areas of the collection, which are actually of a major interest to the parent organization that is, BARC. The subject areas when arranged according to the Bradford's zones the ratio of zones was observed as 2:5:20 (1:n:n²). This ratio shows that BARC library book collection almost obeys the Bradford's law. In this analysis, we also tried to draw the Bradford's curve for the book collection, which almost matched to the ' $S$ ' shaped Bradford's curve.
\end{abstract}

Keywords: Collection development, collection evaluation, scientometrics, Bradford's law

\section{INTRODUCTION}

\section{Collection Development}

Collection development is a very important process for the growth of a library. It is a planned systematic development of the library collection. It is the process of linking all the decisions of the management to the user community on the basis of their needs. It is a continuous and dynamic activity to develop a need based, user responsive, up-to-date and balanced collection fit to meet the document and

*Address for correspondence:

E-mail: priyavg@barc.gov.in

\begin{tabular}{|l|l|}
\hline \multicolumn{2}{|c|}{ Access this article online } \\
\hline Quick Response Code: & \\
\hline & Website: \\
\hline & www.jscires.org \\
\cline { 2 - 2 } & DOI: \\
\hline
\end{tabular}

information needs of users. Main goal of the library is to fulfill the information needs of the organization for achieving the set objectives. Library plays this role by providing a balanced collection of information as well as giving different kinds of information services.

Process of collection development comprises the following activities: $^{[1]}$

- Collection and analysis of information/documents needs of users

- Scientific selection of materials to meet the organizational objectives and goals

- Planned acquisition of balanced collection

- Regular evaluation of the collection

- Proper maintenance of the collection

- Proper utilization of funds.

Evaluation of Collection

Collection development plays a vital role for achieving the objectives of the organization. Parent organization allocates a 
very big share of its budget for the development of rich and balanced collection, which ultimately helps the users to move toward the achievement of the objectives. The collection should be evaluated to see whether it meets the satisfaction levels of its users as well as to see whether it is growing in the proper direction to support the organizational activities.

The American Library Association (ALA) guide to the evaluation of library collections ${ }^{[2]}$ divides the method of evaluation into collection centered and use-centered measures. The guide summarizes major techniques to evaluate the library collection as:

- Collection centered:

- Checking lists, bibliographies, and catalogs

- Expert opinions

- Comparative use statistics

- Collection standards.

- Use-centered:

- Circulation studies

- User studies

- Analysis of Inter Library Loan statistics

- Citation studies

- Shelf availability

- Simulated use studies

- Document delivery tests.

\section{Bhabha Atomic Research Centre Library}

Bhabha Atomic Research Centre (BARC) is a premier institute to the country of India for its research and development in the field of peaceful uses of atomic energy. The library of BARC that is, Scientific Information Resource Division (SIRD) helps its scientists by providing the scientific literature in their subject areas in different forms as books, periodicals, reports, databases e-resources as well as by providing different kinds of information services. SIRD is a special scientific library with special clientele having special subject interest. The book collection of this library is always been developed in such a way that helps its scientists to satisfy their information needs for keeping them up-to-date regarding the relative research activities around the world. SIRD invites recommendations from scientists in BARC for purchasing new books. Furthermore, there is a book selection committee comprising scientists presenting different subject areas dealt in BARC. In general, in multidisciplinary environment, the requirement of different resources including books is highly specialized and no single agency is capable of handling this efficiently. In order to meet this demand and also to utilize the funds effectively, there is an internal mechanism developed for books. The mechanism identifies the experts in various domains and also makes them aware the recent advances. This needs a completely dynamic library professionals and subject experts to come together and logically arrive at the conclusion for selection and identify the need. This need also varies with time as specialized branches evolve gradually and grow independently/merge into broad domains. This committee also gives recommendations for new books. This way the collection of this library is developed to become a balanced collection. BARC spends a big amount of its budget for purchase of books, databases, standards, journals, reports, etc., Hence, it is very necessary to evaluate the collection of this special scientific library of BARC to see whether it is growing parallel to the subject interests of its scientists.

\section{Bradford's Law}

Bradford's law, first published in: "Engineering"[3] 137:85-86 by Bradford in 1934, then in his book "documentation." "[4] Bradford's law of scattering (of subjects in information sources) is often mentioned together with Zipf's law (about word frequencies in natural language texts) and Lotka's law (about distribution of authors productivity) as one among the three most important bibliometric laws and is often considered the best model or example of scientific research in the field of Library and Information Science. Bradford's law states that documents on a given "subject" is distributed (scattered) according to a certain mathematical function so that a growth in papers on a subject requires a growth in the number of journals/information sources. The numbers of the groups of journals to produce nearly equal numbers of articles is roughly in proportion to $1: n: n^{2} \ldots$, where $n$ is called the Bradford's multiplier. ${ }^{[5]}$

Bradford first applied his law to examine all of the journal titles contributing to a bibliography on applied geophysics. He discovered that he could divide the titles in three groups, such that each group of titles contributed about the same number of articles. Starting with the titles which contributed the most articles, he divided the articles into three equal groups:

- The first 9 titles contributed 429 articles,

- The next 59 titles contributed 499 articles,

- The last 258 titles contributed 404 articles.

The value of this arrangement lies in the number of titles it takes for each one-third of the articles. In this case, Bradford discovered regularity in calculating the number of titles in each of the three groups:

- 9 titles 
- $9 \times 5$ titles (equals 45 titles)

- $9 \times 5 \times 5$ titles (equals 225 titles).

Just as the three groups of articles were not quite equal in size, this formulation does not quite give the observed number of titles. This arrangement does have a very special regularity. There is a "core" of nine titles, which contributes one-third of all the articles. In order to get the second third of the articles (that is, to add the same number of articles already found), one needs to search 5 times as many titles $(5 \times 9)$. To find the last third of the articles (again, to add the same number of articles as found in the "core" titles), one must search 5 times again $(9 \times 5 \times 5)$ as many titles. Thus to show title groups contributing an equal number of articles, one can write:

\section{$9: 9 \times 5: 9 \times 5^{2}$}

Recognizing that the size of the core (9) and the multiplier (5) might be different for other searches, we divide the group by nine and replace the multiplier with a variable. ${ }^{[6]}$ This gives groups of titles with sizes:

1:n: $\mathrm{n}^{2}$

The figure below shows the positions of different zones of Bradford's law.

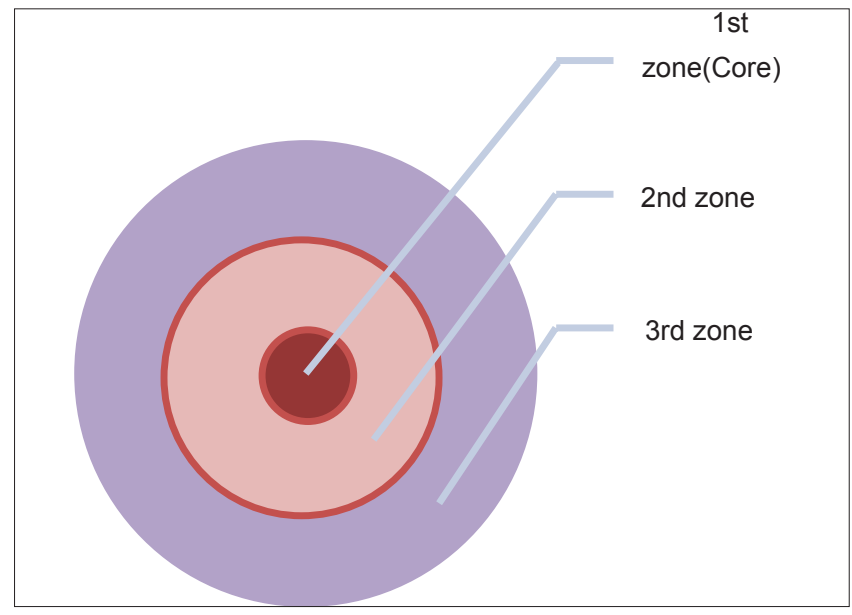

\section{Applications of Bradford's Law}

Basically Bradford used this law for developing the collection of journals. After that many commentators have used Bradford law to solve the practical problems related to information seeking and retrieval. White ${ }^{[7]}$ proposed an automatic option for sorting the output from online searches of journal literature. He did the computerized sorting of the hits by the journals in which they appear and then of journals, high to low, by the number of hits appearing in each. He termed the procedure "Bradfordizing" and stated the ability to retrieve the items selectively by the journal after learning contributing titles and their yields.

Main uses of Bradford's law are:

- In selection as well as deselection of materials

- Defining the core collection

- Collection evaluation

- The law of diminishing returns

- Calculation of costs at various coverage that is, cost-effectiveness

- Setting priorities among different types collections.

\section{OBJECTIVES}

Bradford's law has been used to analyze the journal collection. In this study, we are applying this law to the evaluation of books collection developed by SIRD, BARC that is, BARC central library. Bradford law has used the terms number of articles and number of journals. We have replaced these terms with the number of books and number of subjects, respectively. The main objectives of the study are:

- To see whether the collection of books obeys the Bradford's law

- To evaluate the collection using Bradford's law for the core areas of the book collection.

\section{METHODOLOGY}

For this study, we have considered the book collection of SIRD added to the library until December 2011 from its inception. We downloaded all the bibliographic details of the books in this period. A total of 94,450 books from above stated period are considered for the study. All these books are categorized broadly in different subject categories on the basis of the class numbers assigned. After categorizing subtotals are made for each subject categories. These subject categories were then arranged in descending order for dividing them into three zones of Bradford that is, core zone, second zone and last zone with almost equal number of books in each zone. The categories divided into three zones are then analyzed with their subject contents to see whether it obeys the Bradford's law.

\section{ANALYSIS}

\section{Categorization of Total Collection into Broad Subject Headings}

The total collection of 94,450 books of BARC library that is, SIRD was categorized into different broad subject headings on the basis of Universal Decimal 
Classification (UDC) class numbers. The total collection was divided into around 27 main subject headings as shown in Table 1. It also shows the percentage share each subject heading is carrying in the total collection. Figure 1 shows the graphical presentation of the top ten subject headings of the collection. Table 1 as well as Figure 1 shows that

Table 1: Total list of subject headings with its percentage share

\begin{tabular}{lcc}
\hline Sub. heading & $\begin{array}{c}\text { No. of } \\
\text { books }\end{array}$ & $\begin{array}{c}\text { Percentage } \\
\text { share }\end{array}$ \\
\hline Nuclear physics & 14937 & 15.81 \\
Nuclear Engineering & 12543 & 13.28 \\
Chemistry & 11447 & 12.12 \\
Medical Sciences/Health and Safety & 8545 & 9.05 \\
Mathematics & 5174 & 5.48 \\
Computer Science & 4816 & 5.10 \\
Life Sciences & 4703 & 4.98 \\
Materials Science & 3793 & 4.02 \\
Electronics and Telecommunications & 3420 & 3.62 \\
Manufacturing Technology & 3296 & 3.49 \\
Humanities and Social science & 3262 & 3.45 \\
Electrical Engineering & 3259 & 3.45 \\
Geology & 2404 & 2.55 \\
Agricultural Science & 1957 & 2.07 \\
General & 1792 & 1.90 \\
Library Science, reference work & 1563 & 1.65 \\
Geography/Biography/History & 1180 & 1.25 \\
Management & 1120 & 1.19 \\
Environmental Science & 1114 & 1.18 \\
Art and Culture & 970 & 1.03 \\
Botany & 836 & 0.89 \\
Astronomy & 811 & 0.86 \\
Biotechnology & 680 & 0.72 \\
Zoology & 501 & 0.53 \\
Instrumentation & 276 & 0.29 \\
Domestic Science-Housekeeping & 39 & 0.04 \\
Palaeontology & 12 & 0.01 \\
\hline
\end{tabular}

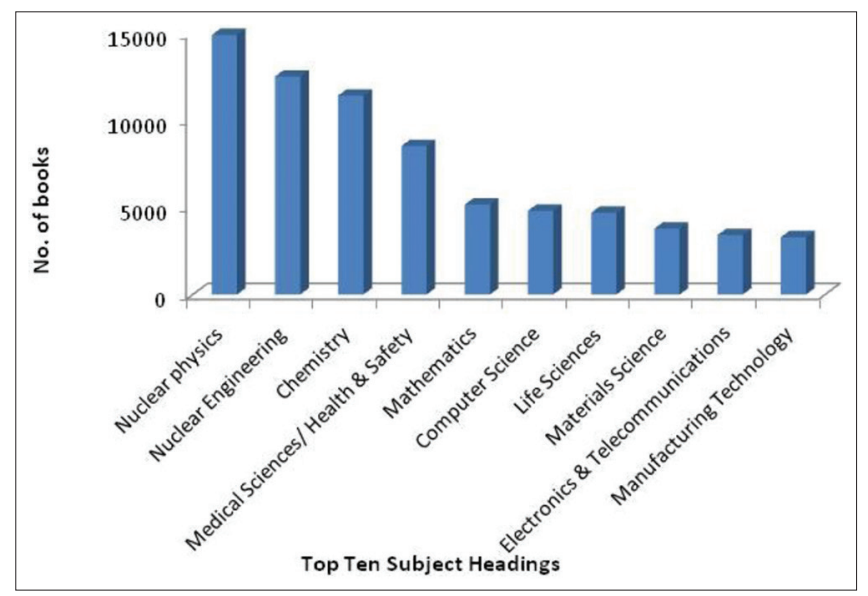

Figure 1: Top ten subject headings of the collection nuclear physics $(15.81 \%)$ topped the list followed by nuclear engineering (13.28\%), chemistry (12.12\%), medical sciences $(9.05 \%)$, and mathematics $(5.48 \%)$.

\section{Bradford's Application to the Collection}

The 27 subject headings assigned to the book collection are then arranged in descending order according to the number of books in it. Table 1 shows for descending order of subject headings. Total collection of 94,450 with 27 subject headings are then divided into three equal zones having approximately same number of books. Table 2 shows the distribution of subject headings and corresponding number of books into three zones. It shows that the I zone that is, core zone with first two subject headings of Table 1 contributed 27,480 books, II zone having next five subject headings contributed 34,685 books and III zone having next twenty subject headings contributed 32,285 books.

\section{Calculation of the Bradford's Law}

Bradford law that is, 1:n: $\mathrm{n}^{2}$ was initially applied to journal collection. Here, in this case, we have considered the number of books in place of number of articles and number of subject headings in place of number of journals. Hence, when we applied the Bradford's formula to our collection we got the ratio as 2:5:20.

\section{Calculating the Bradford's Multiplier}

The Bradford's multiplier factor was arrived at by dividing number of subject headings of a zone by its preceding zone. It is also expressed as the ratio of the number of subject headings in any group to the number of subject headings in any immediately preceding group. ${ }^{[8]}$

So, mean value of Bradford's multiplier is

$$
=\frac{(5 / 2)+(20 / 5)}{2}
$$

$=3.25$

So if we apply this multiplier to our zones, then the Bradford formula becomes,

- $1: \mathrm{n}: \mathrm{n}^{2}$

- $2: 2 \times 3.25: 2 \times 3.25 \times 3.25$

- $2: 6.25: 21.12$.

This calculation is almost matching to the results that is, 2:5:20 which we got from the analysis of Table 2. So, we can say that our collection is almost obeying the Bradford's law. 


\section{Evaluation of Collection using Bradford's Law}

The above calculation showed that out collection almost obeys the Bradford's law. This law gave rise to the core areas of the collection of BARC library. Table 3 shows the zone wise positions of different subject categories. Nuclear physics and nuclear engineering are forming the I zone which is core zone of the collection. Since BARC deals mainly in subject area of nuclear science and technology, we can say that BARC library is supporting to the interest of its parent organization. II zone consists of chemistry, medical sciences, mathematics, computer science and life science. BARC also carries out research in these fields. Second zone subject areas are also equally important areas as that of zone I subject areas to BARC.

Table 2: Collection divided into three zones according to Bradford's law

\begin{tabular}{lcc}
\hline Zone & No. of subjects & No. of books \\
\hline I (core) & 2 & 27480 \\
II & 5 & 34685 \\
III & 20 & 32285 \\
\hline
\end{tabular}

Table 3: Zone-wise list of subject headings

\begin{tabular}{lcc}
\hline Sub. heading & Total & Zones \\
\hline Nuclear physics & 14937 & I \\
Nuclear Engineering & 12543 & \\
Chemistry & 11447 & II \\
Medical Sciences/Health and Safety & 8545 & \\
Mathematics & 5174 \\
Computer Science & 4816 \\
Life Sciences & 4703 & \\
Materials Science & 3793 \\
Electronics and Telecommunications & 3420 \\
Manufacturing Technology & 3296 \\
Humanities and Social science & 3262 & \\
Electrical Engineering & 3259 \\
Geology & 2404 \\
Agricultural Science & 1957 \\
General & 1792 \\
Library Science, reference work & 1563 \\
Geography/Biography/History & 1180 \\
Management & 1120 \\
Environmental Science & 1114 \\
Art and Culture & 970 \\
Botany & 836 \\
Astronomy & 811 \\
Biotechnology & 680 \\
Zoology & 501 \\
Instrumentation & 276 \\
Domestic Science-Housekeeping & 39 \\
Palaeontology & 12 & \\
\hline
\end{tabular}

Zone III contains many small areas, which are required in support to major areas. Also it includes many areas of social as well general interest of the people of this organization.

\section{Core Group Clusters}

We have divided the collection in broad subject headings with the help of UDC. These subject headings are actually the clusters of narrower subjects falling in that category. The clusters of core group containing two subject headings as nuclear physics and nuclear engineering are shown in Figures 2 and 3. Figure 2 is (i.e. nuclear physics cluster) is made up of the combination of the narrower subjects as physics (9295) and nuclear physics (5642). Figure 3 that is, nuclear engineering cluster is made up of different areas of engineering aspects. Even though main research area of BARC is nuclear engineering, many other engineering fields are required as the accompaniment to the major nuclear engineering areas. Nuclear engineering cluster is made up of nuclear engineering (6499), workshop practice (1663), civil engineering (819), robotics/control systems (667), energy (506), engineering and technology-general (482), aeronautical engineering/space engineering (381), mining and mineral dressing (283), fluid engineering/piping technology (267), military science warfare (237), cryogenics (199), mechanical engineering (168), combustion engines (116), pneumatic machines (112), applied sciences (47), hydraulic engineering (43) machinery operations and maintenance (33) and traffic routes on land (21). Though these areas does not fall directly under the nuclear engineering but they have used for different kinds of processes used in nuclear engineering, so these are categorized in to the subject heading of nuclear engineering.

\section{Bradford's S-shaped Curve}

Bradford's curve or graph is drawn as the cumulative number of source items versus logarithm of the cumulative number of journals. The standard Bradford curve takes the shape of ' $\mathrm{S}$ '. In this analysis we have also tried to draw the Bradford's curve. Figure 4 shows the Bradford curve drawn as logarithm of the number of subjects versus cumulative number of books comparing with the perfect Bradford's curve as ' $\mathrm{S}$ ' shape. The graph begins as a rising curve and then continues as a straight line. The rising part of the curve shows the core subject headings of the collection analyzed. Even though, it is not showing perfect $S$ shape, it is almost matching the same. 


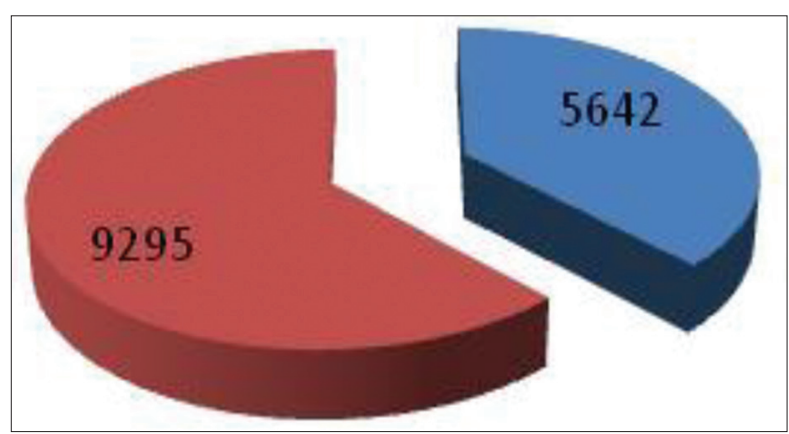

Figure 2: Nuclear Physics cluster

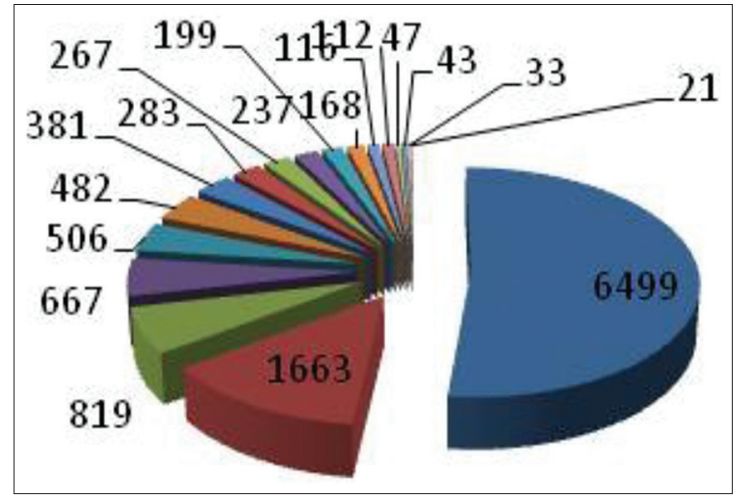

Figure 3: Nuclear engineering cluster

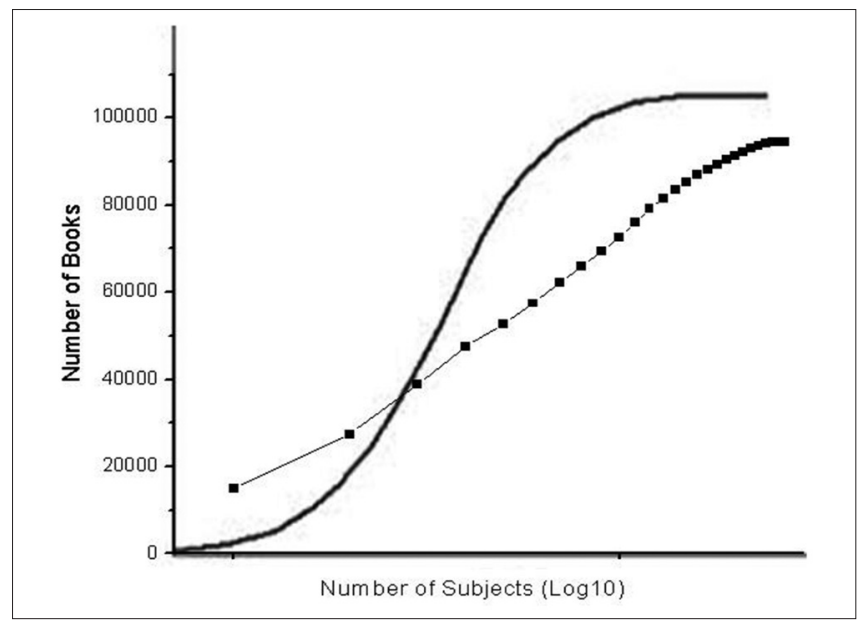

Figure 4: Collection showing Bradford's S-shaped curve

\section{CONCLUSION}

BARC library is a special scientific research library which provides exhaustive information in the field of nuclear science and technology and allied fields. The present analysis shows that the collection almost obeys the Bradford's law (having ratio as 2:5:20) and it is developing towards the requirement of the parent organization. Table 1 shows that the collection on the subject nuclear physics, which is the main thrust area of this organization tops the list. When we applied the Bradford's law to the collection to find out the core areas of the collection we found that nuclear physics and nuclear engineering are the core areas based on the number of book collection of BARC library. There are many other subjects such as chemistry, computer science, materials science, electronics and telecommunications etc., which should have been ranked in the I zone according to the subject interest of the parent organization. However, they are falling in II or III zones because of the number of the books in the collection in that subject areas. So, the collection in these areas can be given the attention so that collection in these areas can be improved further to reach the satisfactory levels. Furthermore, the core areas being the foremost important areas of BARC research should be given the attention to maintain their top positions in the collection.

\section{REFERENCES}

1. Majeed KC. Collection Development in College Libraries. New Delhi: Ess Ess Publications; 2000. p. 313.

2. The ALA Guide to the Evaluation of Library Collections. American Library Association; 2008.

3. Bradford SC. Sources of information on specific subjects. Engineering 1934;137:85-6.

4. Bradford SC. Documentation. London: Crosby Lockwood and Sons; 1948.

5. Birger H, Jeppe N. Bradford's law of scattering: Ambiguities in the concept of "subject". CoLIS 2005. Berlin: Springer-Verlag; 2005. p. 96-106.

6. Carl DM. Bradford's law: Theory, empiricism and the gaps between. Libr Trends 1981;30:42-52.

7. White HD. "Bradfordizing" search output: How it would help online users. Online Rev 1981;5:47-54.

8. Sudhier KG. Application of Bradford's law of scattering to the physics literature: A study of doctoral theses citations at the Indian Institute of Science. DESIDOC J Libr Inf Technol 2010;30:3-14.

How to cite this article: Girap P, Ashok T, Bhanumurthy K. Application of Bradford's law to the evaluation of book collection of library of Bhabha Atomic Research Centre. J Sci Res 2014;3:22-7.

Source of Support: Nil, Conflict of Interest: None declared 